\title{
Vein of Galen Aneurysm: Prenatal Ultrasound Diagnosis
}

\section{Aneurisma da Veia de Galeno: Diagnóstico Ecográfico Pré-Natal}

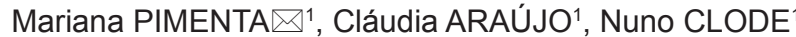

Acta Med Port 2020 Jul-Aug;33(7-8):521-521 - https://doi.org/10.20344/amp.11831

Keywords: Prenatal Diagnosis; Ultrasonography, Prenatal; Vein of Galen Malformations / diagnostic imaging

Palavras-chave: Diagnóstico Pré-Natal; Malformações da Veia de Galeno; Ultrassonografia Pré-Natal

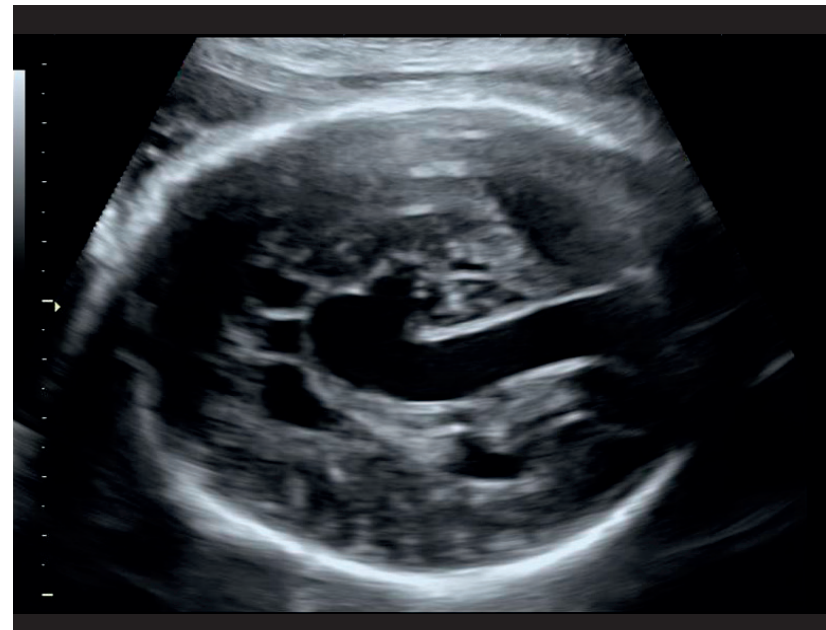

Figure 1 - Dilated cerebral midline anechoic tubular structure draining into a dilated sagittal sinus: keyhole appearance

A 39-year-old woman, with a low risk pregnancy and normal ultrasound findings during the first and second trimesters, performed an ultrasound at 32 weeks that revealed a large anechogenic tubular structure, located in the midline of the fetal brain, supratentorial and non-pulsatile with a characteristic keyhole appearance (Fig. 1) and an internal turbulent flow (Fig. 2), suggesting the diagnosis of aneurysm of the vein of Galen. ${ }^{1-3}$ This is a rare arteriovenous anomaly, comprising less than $1 \%$ of all intracranial

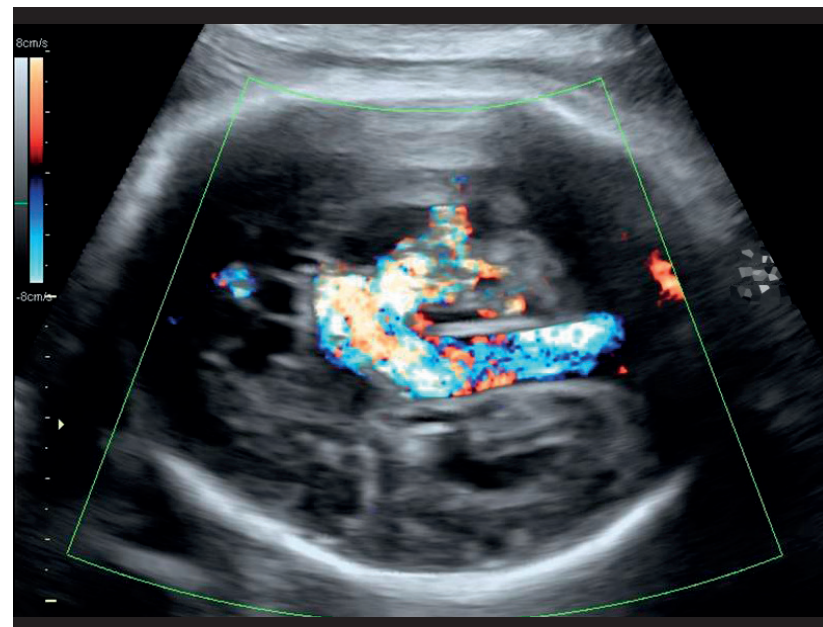

Figure 2 - Characteristic turbulent flow showed with color Doppler

vascular malformations, usually diagnosed during the third trimester with ultrasound color Doppler. ${ }^{3}$ Intrauterine signs of congestive cardiac failure are common and worsen the prognosis. ${ }^{4,5}$ In this case, fetal echocardiograms revealed cardiomegaly with progressive right sided cardiac dilatation and tricuspid regurgitation; signs of heart failure (ascites and pericardial effusion) emerged. At 39 weeks, a $3038 \mathrm{~g}$ female infant was delivered by cesarean section and died nine hours later due to multi-organ failure.

PROTECTION OF HUMANS AND ANIMALS: The authors declare that the procedures were followed according to the regulations established by the Clinical Research and Ethics Committee and to the Helsinki Declaration of the World Medical Association.

DATA CONFIDENTIALITY: The authors declare having followed the protocols in use at their working center regarding patients' data publication

INFORMED CONSENT: Obtained.

CONFLICTS OF INTEREST: All authors report no conflict of interest.

FUNDING SOURCES: The authors declare that there were no external sources of study for the performance of this article.

\section{REFERENCES}

1. Santo S, Pinto L, Clode N, Cardoso E, Marques JP, Melo A, et al. Prenatal ultrasonographic diagnosis of vein of Galen aneurysms - report of two cases J Matern Fetal Neonatal Med. 2008;21:209-11.

2. Sepulveda W, Platt C, Fisk N. Prenatal diagnosis of cerebral arteriovenous malformation using color Doppler ultrasonography: case report and review of the literature. Ultrasound Obstet Gynecol. 1995;6:282-6.

3. Mai R, Rempen A, Kristen P. Prenatal diagnosis of a vein of Galen aneurysm assessed by pulsed and color Doppler sonography. Ultrasound Obstet Gynecol. 1996;7:228-30.

4. Has R, Gunay S, Ibrahimoglu L. Prenatal diagnosis of a vein of Galen aneurysm. Fetal Diagn Ther. 2003;18:36-40.

5. Sasidharan CK, Anoop P, Vijayakumar M, Jayakrishnan MP, Reetha G, Sindhu TG. Spectrum of clinical presentations of vein of galen aneurysm. Indian J Pediatr. 2004;7:459-63.

1. Departamento de Obstetrícia, Ginecologia e Medicina da Reprodução. Hospital de Santa Maria. Centro Hospitalar Universitário Lisboa Norte. Lisboa. Portugal.

$\bowtie$ Autor correspondente: Mariana Pimenta. marianamgpimenta@gmail.com

Recebido: 19 de janeiro de 2019 - Aceite: 09 de julho de 2019 | Copyright @ Ordem dos Médicos 2020 